\title{
A Consensus Statement on a Better Response to Alcohol Related Problems prepared at a Meeting held on 6 November 1987 at the Royal College of Psychiatrists
}

The first consensus statement to be agreed by representatives of all the Medical Royal Colleges* calls for the Government to give a lead in reducing the damage caused by alcohol by taking measures which would reduce overall consumption.

\section{Introduction}

In 1986 The Royal College of Psychiatrists produced a report entitled Alcohol: our Favourite Drug. Shortly after this, The Royal College of General Practitioners, The Royal College of Physicians of London and The British Psychological Society all produced reports expressing concern about alcohol as a hazard to health. All four recognised that in the past 25 years alcohol consumption per head of the UK's adult population had risen by more than $50 \%$ with devastating consequences for the health of the nation.

In this paper it is not necessary to catalogue the range of alcohol-related problems which cause concern. They include: cirrhosis of the liver, road traffic and other accidents, various varieties of cancer, hypertension and cardiovascular disease, endocrine dysfunction and a wide variety of mental health and social problems. The social costs of alcohol misuse have been conservatively estimated in 1985 at $£ 1,846$ million per annum. The World Health Organization has included over-use of alcohol as one of its targets of health damaging behaviour and has asked member states to aim at reducing the consumption of alcohol by at least $25 \%$ by the year 2000 . This recommendation was endorsed by the Government.

In the face of such widespread medical concern, we felt it timely to see how far significant medical interest within Britain could reach a consensus about the formulation and implementation of a better response to alcohol-related problems in our society.

We believe that the primary aim of all strategies must be the reduction of harm related to alcohol consumption. The following framework of action commands wide measure of agreement within the medical and allied professions:

\section{Framework for action}

Reduction of overall alcohol consumption

Policies on alcohol problems should give much greater emphasis to prevention. Reduction in overall alcohol consumption must be viewed as a necessary public health measure to achieve this aim. Many different approaches are necessary.

*A list of participants is given in Appendix I.

\section{Call for Government to increase price on alcohol}

There is a clear association between the price of alcohol in relation to disposable income, the level of consumption in the community and the prevalence of alcohol-related harm. We would recommend that Government fiscal policy should be intentionally employed to ensure that per capita consumption is gradually reduced.

\section{Extension in licensing hours to be resisted}

The extension in licensing hours will increase the availability of alcohol and from all that we know this will increase consumption and therefore should be resisted. Proper enforcement of existing licensing laws and preventive policing will bring about a reduction in drink related problems.

\section{Limitation of alcohol advertising}

Advertising at present often contravenes existing guidelines. The scale and content of alcohol advertising, both direct and indirect, such as sponsorship, should be stringently monitored by independent assessors. Further curtailment may be necessary if the guidelines continue to be contravened.

\section{Introduction of random breath testing}

In order to reduce the extent of driving after drinking, highly visible random breath testing must be introduced, which will be in addition to existing discretionary tests. Such a measure must be part of a well publicised campaign. This needs to be accompanied by appropriate public education. This measure, which would reduce the number of road traffic accidents and save lives and injury, now has a major degree of public support and should be implemented urgently.

\section{Lowering limits for drinking and driving}

We recommend lowering the limits for drinking and driving. As a large number of drink driving offences occur amongst inexperienced drivers, a first step should be to lower the permitted level of blood-alcohol for drivers in the first two years of passing their driving test.

Promote alcohol consumption limits for men and women Medical opinion agrees that sensible drinking implies not more than 21 units a week for men and not more than 14 units a week for women and abstinence or no more than an occasional drink during pregnancy. Public education about sensible drinking should be widely promoted. Doctors have 
a responsibility to educate the public on these sensible limits of alcohol consumption. This should become an integral part of health promotion in medical practice.

\section{Government finance of public education campaign}

Education is needed to make clear: the relationship between drinking and harm; the personal responsibilities for choices about drinking; the need for community support for national alcohol policies. There should be increased Government commitment and commitment of local and health authorities towards public information and education about alcohol. Research is required on the development of improved techniques for health education. These developments should be properly funded and evaluated.

Clear labelling of beverages with strength and amount of alcohol content

Alcohol manufacturers should be required to label clearly their beverages with their strength and alcoholic content. Labelling should be easily understood, i.e. as units of alcohol.

\section{Alcohol education for medical profession}

Improved and better integrated education about alcohol is urgently needed for medical students and doctors. They should be helped to become aware of their attitudes to alcohol and towards its problems, and receive training in the early detection of people at risk.

\section{Exemplar role of the medical profession}

The medical profession must consider setting an example in relation to responsible drinking practices, particularly in the working environment. They should respond in a helpful way towards colleagues who have alcohol problems.

Ensure that adequate and early help is available to every problem drinker and the family where relevant

Treatment and counselling is eminently feasible, especially in early stages and there is justification for greater therapeutic optimism. Emphasis should be placed on early intervention and health promotion within Primary Health Care and hospital settings including the Occupational Health Service. This development will also require strengthening of specialised support services in both the statutory and non statutory sectors.

\section{Increase research funding}

To implement a more effective public health and treatment response to alcohol problems, a much higher level of funding of research is required. Research workers must be prepared to discuss their findings both with the public and the government in a way which is easily understood.

\section{Conclusion}

Some of these objectives are addressed to the training and activities of the medical profession. Others will require government action and public health measures. Still others are addressed to the individual and involve the individual taking responsibility for his/her own health. We believe that there is an urgent need for a more carefully co-ordinated and conspicuous government policy towards alcohol and to this end we welcome the creation of a Ministerial Group on Alcohol Misuse chaired by the Lord Privy Seal, the Rt Hon John Wakeham MP, who will receive a copy of this statement.

\section{REFERENCES}

Royal College of General Practitioners (1986) Alcohol a Balanced View. London: Royal College of General Practitioners.

Royal College of Physicians (1987) A Great and Growing Evil. London: Tavistock.

Royal College of Psychiatrists (1986) Alcohol our Favourite Drug. London: Tavistock.

WorLd Health Organization (Europe) (1985) Targets for Health for All. Copenhagen: WHO.

FACULTY OF COMMUNITY MEDICINE (1986) Health for All by the Year 2000: Charter for Action. London: Faculty of Community Medicine.

British Psychological Society (1986) Psychological Aspects of Alcoholism. Leicester: British Psychological Society.

\section{APPENDIX I}

Representatives from the following organisations participated

Action on Alcohol Abuse

Alcohol Concern

British Psychological Society

Faculty of Community Medicine

Faculty of Occupational Medicine

Health Education Authority

Medical Commission on Accident Prevention

Medical Council on Alcoholism

Royal College of General Practitioners

Royal College of Obstetricians and Gynaecologists
Royal College of Pathologists Royal College of Physicians

Royal College of Physicians of Edinburgh

Royal College of Physicians of Ireland

Royal College of Physicians and Surgeons of Glasgow

Royal College of Psychiatrists

Royal College of Surgeons of England

Scottish Council on Alcohol

Scottish Health Education Group

Welsh Council on Alcoholism 